\section{B A Institute of \\ YK Business Administration \\ तर Karachi \\ Leadership and Ideas for Tomorrow}

Article 4

Volume 2 Issue 1 January - June 2007

$1-1-2007$

\title{
On predictability in South Asian stock markets
}

Khurshid M. Kiani

The University of West Indies, Kingston, Jamaica, West Indies

Follow this and additional works at: https://ir.iba.edu.pk/businessreview

Part of the Finance and Financial Management Commons

(c) (7)

This work is licensed under a Creative Commons Attribution 4.0 International License.

\section{Recommended Citation}

Kiani, K. M. (2007). On predictability in South Asian stock markets. Business Review, 2(1), 14-30. Retrieved from https://doi.org/10.54784/1990-6587.1111

This article is brought to you by iRepository for open access under the Creative Commons Attribution 4.0 License and is available at https://ir.iba.edu.pk/businessreview/vol2/iss1/4. For more information, please contact irepository@iba.edu.pk. 


\title{
ARTICLE
}

\section{On Predictability in South Asian Stock Markets}

\author{
Khurshid M. Kiani \\ The University of West Indies, Kingston, Jamaica, West Indies
}

\begin{abstract}
In this research I investigate persistence in monthly excess stock returns over risk free rates in two South Asian stock markets i.e. S\&P CNX 500 and KSE 100 stock price indexes using non-Gaussian state space or unobservable component model with stable distributions and volatility persistence.

Results from non-Gaussian state space models show that both markets encompass volatility persistence. KSE 100 has a stable characteristic exponent of $\alpha 1.748$, but for S\&P CNX 500 index the value for the characteristic exponent $\alpha$ is 1.999 which shows normal behavior in this market. Both markets encompass persistent signal in returns at $10 \%$ level of significance. The efficiently estimated excess returns for $S \& P$ CNX 500 are $0.01 \%$ per month $(0.12 \%$ per annum), and $0.015 \%$ per month $(0.18 \%$ per annum) for KSE 100 index.
\end{abstract}

Key phrases: stock return predictability; unobserved components; fat tails; stable distributions

JEL Codes: $C 22, C 53, G 14$

Word Count Main Text: 2434

\section{INTRODUCTION}

$\mathrm{F}$ ama (1991) shows that predictability in stock returns have been explored extensively $\mathrm{H}$ in the literature. The motive behind exploring stock returns predictability is economic gains that could be attained due to suitable trading strategies (Xu 2004). However, researchers have focused on two aspects of empirical distribution of stock returns which they think are important for accurate predictability. For example, Akgiray and Booth (1986), Jensen (1991), de Vries (1991), Buckel (1995), Mantegna and Stanley (1995), and McCulloch (1997) found evidence of non-normality in stock returns. On the other hand Nelson (1991) Danielsson (1994), Pagan and Schwert (1990), Diebold and Lopez (1995), and Goose and Kroner (1995) found evidence of volatility persistence in stock returns.

Conard and Kaul (1988) employed state space or unobservable component model to predict stock returns considering that shocks in both the observation and state Equations are normal. Similarly, state space models have also been used by Harvey (1985) and Watson (1986) with the assumptions that the underlying errors are normal. However, McCulloch (1996a) and Bidarkota and McCulloch (2004) modeled stock returns to be non-Gaussian with fat tails. 
In this study, I investigate possible existence of persistent predictable signal in monthly S\&P CNX 500 and KSE 100 indexes excess returns over the respective risk free rates. In order to account for non-Gaussian data, I model returns within the framework of Parisian stable distributions that were also employed by Mantangna and Stanley (1995), Buckel (1995), and McCulloch (1997). Therefore, as in Oh (1994) and Bidarkota and McCulloch (1998), I relax normality assumption in favor of stable distributions because Kalman filter is not operable efficiently with stable distributions. Similarly, to explicitly account for volatility persistence in the return series I employ GARCH-like model. The motive behind this study is to find stock market predictability in KSE 100 index (Pakistani stock market) and compare it with neighboring south Asian stock market (S\&P CNX 500: Indian Stock Market). The findings from this study are intended to help policymakers as well as business community in Pakistan.

The remaining paper is organized as follows. Section 2 outlines the most general model used in this paper, and some estimation issues. In section 3, I present data sources, empirical results, and hypotheses tests, and finally section 4 includes conclusions of the study.

\section{STATE SPACE MODEL FOR STOCK RETURNS}

In this research six versions state space or unobserved time series econometrics models are used. Model 1 is the most general model that encompasses unobservable component in stock returns including non-normal errors and GARCH-like effects which is shown in following thee Equation:

$$
\begin{aligned}
& r_{t}=x_{t}+\varepsilon_{t} \quad \varepsilon_{t} \sim c_{t} z_{1 t}, \quad z_{1 t} \sim \text { iid } s_{\alpha}(0,1) \\
& (x-\mu)=\phi\left(x_{t-1}-\mu\right)+\eta_{t} \quad \eta_{t} \sim c_{\eta} c_{t} z_{2 t} \\
& z_{2 t} \sim \text { iid } \quad S_{\alpha}(0,1) \\
& c_{t}^{\alpha}=\omega+\beta c_{t-1}^{\alpha}+\delta\left|r_{t-1}-E\left(r_{t-1} \mid r_{1}, \ldots ., r_{t-2}\right)\right|^{\alpha} \\
& +\gamma d_{t-1} \mid r_{t-1}-E\left(r_{t-1}\left|r_{1}, \ldots ., r_{2-1)}\right|^{\alpha}\right.
\end{aligned}
$$

Where,

$$
d_{t-1}= \begin{cases}1 & \text { if } r_{t-1}-E\left(r_{t-1} \mid r_{1}, r_{2}, \ldots \ldots \ldots, r_{t-2}\right)<0 \\ 0 & \text { otherwise }\end{cases}
$$

Here $r_{t}$ is the observed one-period excess return, $x_{t}$ is an unobserved persistence components in the series, and $Z_{1}$ and $Z_{2}$ are independent white noise processes. 
Model 2 is obtained restricting $\alpha=2$ in model 1 which can be written as:

$$
\begin{aligned}
& r_{t}=x_{t}+\varepsilon_{t}, \varepsilon_{t} \sim \sqrt{2} c_{t} z_{1 t}, \quad z_{1 t} \sim \text { iid } N(0,1) \\
& \left(x_{t}-\mu_{t}\right)=\phi\left(x_{t-1}-\mu\right)+\eta_{t}, \quad \eta_{t} \sim \sqrt{2} c_{\eta} c_{t} z_{2 t}, \quad z_{2 t} \sim \text { iid } N(0,1) \\
& c_{t}^{2}=\omega+\beta c_{t-1}^{2}+\delta\left|r_{t-1}-E\left(r_{t-1} \mid r_{1}, r_{2}, \ldots \ldots, r_{t-2}\right)\right|^{2}+\gamma d_{t-1}-\left.E\left(r_{t-1} \mid r_{1}, r_{2}, \ldots, r_{t-2}\right)\right|^{2}
\end{aligned}
$$

Setting $\beta=\delta=\gamma=0$ in model 1 gives model 3, which is shown in Equation 3:

$$
\begin{aligned}
& r_{1}=x_{t}+\varepsilon_{t}, \quad \varepsilon_{t} \sim S_{\alpha}(0, c) \\
& \left(x_{t}-\mu\right)=\phi\left(x_{t-1}-\mu\right)+\eta_{t}, \quad \eta_{t} \sim S_{\alpha}\left(0, c_{\eta}, c\right)
\end{aligned}
$$

When restricting $\phi=0$ in model 1 , the shocks $\varepsilon_{t}$ and $\eta_{t}$ are not separately identified so $c_{\eta}$ is also not identified. The resulting model is model 4 which is shown in Equations 4 :

$$
\begin{aligned}
& r_{t}=\mu+\varepsilon_{t}, \quad \varepsilon_{t} \sim c_{t} z_{t}, \quad z_{t} \sim \operatorname{iid} S_{\alpha}(0,1) \\
& c_{t}^{\alpha}=\omega+\beta c_{t-1}^{\alpha}+\delta\left|r_{t-1}-\mu\right|^{\alpha}+\gamma d_{t-1}\left|r_{t-1}-\mu\right|^{\alpha}
\end{aligned}
$$

Where,

$$
d_{t-1}=\left\{\begin{array}{l}
1 \text { if } r_{t-1}-\mu<0 \\
0 \text { otherwise }
\end{array}\right.
$$

Model 5 shown in Equation 5 is obtained setting $\alpha=2$ in model 4 .

$$
\begin{aligned}
& r_{1}=\mu+\varepsilon_{t}, \quad \varepsilon_{t} \sim \sqrt{2} c_{t} z_{t}, \quad z_{t} \sim \operatorname{iid} N(0,1) \\
& c_{t}^{2}=\omega+\beta c_{t-1}^{2}+\delta\left|r_{t-1}-\mu\right|^{2}+\gamma d_{t-1}\left|r_{t-1}-\mu\right|^{2}
\end{aligned}
$$

Restricting $\beta=\delta=\gamma=0$ in model 4 results in model 6 which is presented in Equation 6:

$$
r_{t}=\mu+\varepsilon_{t}, \quad \varepsilon_{t} \sim S_{\alpha}(0, c)
$$

A random variable $\mathrm{x}$ will have stable distribution $S_{\alpha}(0, c)$ when its log characteristic function can be represented as:

$$
\ln E \exp (i x t)=i \delta t-\left|c_{t}\right|^{\alpha}
$$


The parameter $c>0$ measures scale whereas the parameter $\delta(-\infty, \infty)$ measures location and $\alpha \in(o, 2]$ is the characteristic exponent that governs the tail behavior. A small value of $\alpha$ indicates thicker tail and normal distribution pertaining to symmetric stable family encompassing $\alpha=2$ whose variance is equal to $2 c^{2}$.

In the process contained in Equation (1c) we restrict $\omega>0, \beta \geq 0, \delta \geq 0$, and $\gamma \geq 0$. The theoretical term involving dummy variable $d_{t-1}$ captures leverage effects that are transmitted from negative shock to increase in future volatility more than a positive shock of equal magnitude (Nelson 1991, and Hamilton Susmel 1994). Abstracting from the threshold term, when the errors are normal, the model of volatility persistence reduces to GARCH-normal process.

Any predictable variation in excess return is because of persistent component $x_{t}$, which are assumed to follow a simple AR (1) process. When predictable component in Equation 1 becomes significant, than) $E\left(r_{1} \mid r_{1}, \ldots ., r_{t-1}\right)$ provides a useful forecast of returns. However, when $c_{\eta}$ and $\phi$ or one of these is negligible, the returns are purely random, so these may display spurious predictions.

\subsection{Estimation Issues}

Non-Gaussianity of the state space model in Equation 1 creates complication in estimation even without the presence of conditional heteroskedasticity. This happens because the Kalman filter is no longer optimal due to the non-Gaussian nature of shocks.

The general recursive-filtering algorithm due to Sorenson and Alspach (1971) provides optimal filtering and predictive densities under any distribution for the errors and the formula for computing the log likelihood function. These formulae are presented in Appendix-A.

The recursive equation that is employed to compute filtering and predicting densities are given in the form of integrals whose close form analytical expressions are generally intractable, especially in very special cases. In this study, I numerically evaluate these integrals.

Stable distribution and density may be evaluated using Zolotrav's (1986) proper integral representation or by taking inverse Fourier transformation of the characteristic function. However, McCulloch (1996b) has developed a fast numerical approximation to stable distribution and density that has an expected relative density of the precision of $10^{-6}$ for $\alpha \in[0.84,2]$. I, therefore, restrict $\alpha$ in this range for computational convenience.

Lumsdaine (1996) shows that the effect of initial values in GARCH volatility process on the properties of the parameter estimates in $\operatorname{GARCH}(1,1)$ is asymptotically negligible. Diebold and Lopez (1995) suggests to set the initial conditional variance $\left(2 c_{0}^{2}\right.$, where it exists) equal to sample variance at the first iteration and the subsequent 
iterations to sample variance from simulated realizations with estimated parameters (from the previous iterations). Engle and Bollerslev (1986) suggests initializing the $\mathrm{GARCH}$ process using estimates of $\mathcal{C}_{0}$ unconditional value obtained from the volatility process in Equation 1c.

\section{EMPIRICAL RESULTS}

\subsection{Data Sources}

Monthly excess returns in two South Asian stock markets over relevant risk free rates are employed from March 1991 through February 2004. Monthly stock prices for Pakistani stock market index KSE 100 and Indian stock market index S\&P CNX 500 were obtained from Datastream. Pakistan Treasury bill rates and Indian central bank discount rates are the two risk free rates that were obtained from September 2004 version of International Financial Statistic (IFS) CD-ROM. Excess returns are expressed as percent per month throughout the study. Figure 1 plots excess return series for $\mathrm{S} \& \mathrm{P}$ CNX 500 index and Figure 2 plots excess return series for KSE 100 index. The plots shown in these Figures encouraged me to employ models for detecting possible persistence of mean returns using state space or unobserved component model of stock returns.

\subsection{Estimation Results}

Tables 1 and 2 show the estimation results for S\&P CNX 500 and KSE 100 stock price index for different models estimated for this study. These Tables show parameter estimates for characteristic exponent $\alpha$, volatility persistence parameter $\beta, \mathrm{ARCH}$ parameter $\delta$, leverage parameter $\gamma$, signal to noise ratio $c_{\eta}$, and AR coefficient of persistent component of returns $\phi$. There is ample difference in two markets that can be characterized by low values of characteristic exponent $\alpha$, the volatility persistence parameter $\beta$, and high values of leverage parameter $\gamma$ in KSE 100 index compared to S\&P CNX 500. The predictable component in KSE 100 stock price index is statistically significant whereas there is less evidence of statistically significant predictable component in S\&P CNX 500.

Figures 3 and 4 show filter mean $E\left(x_{t} \mid r_{1}, r_{2}, r_{3}, \ldots \ldots, r_{t}\right)$ for Indian and Pakistani stock markets respectively. These plots show that predictable component appear to be constant which indicates that variation in its parameter estimates might not be component in forecasting access returns.

\subsection{Hypotheses Test}

In the following sub-sections the tests for normality, volatility persistence, and persistence in mean returns are elaborated. All tests are based on likelihood ratio test statistics. 


\subsubsection{Test for Normality}

This test is based on the null of $\alpha=2$ in model 1. The LR test statistics for this test has non-standard distribution because the null hypothesis lies on the boundary of the admissible values for $\alpha$; therefore, standard regularity conditions are not satisfied. Inferences are therefore derived from test statistics based on the critical values due to McCulloch (1997).

Based on LR test statistics, the null hypothesis for KSE 100 index can easily be rejected at a significance level of better than 0.005 using critical values from McCulloch (1997). However, using LR test statistics, the null hypotheses of normality, and no volatility persistence for S\&P CNX 500 index is not rejected. The study results indicate that even after accounting for GARCH-like behavior, the excess returns are significantly non-normal.

\subsubsection{Test for Volatility Persistence}

The test for no volatility persistence (homoskedasticity) can be formulated by restricting $\beta=\delta=\gamma=0$ in model 1 . The statistical inferences for this test are based on $\chi_{3}^{2}$ distributions.

The LR for the null of no GARCH which is to test $\beta=\delta=\gamma=0$ reported in Tables 1 and 2 respectively for S\&P CNX 500 and KSE 100 indexes. Homoskedasticity in both the markets is strongly rejected with $\chi_{3}^{2}$ critical values.

\subsubsection{Test for Persistence in Mean Returns}

The null hypothesis for this test is obtained from setting $\phi=2$ in model 1 which assumes that return series are random. In this case the standard likelihood ratio test statistics for this test are not applicable because the two shocks $\varepsilon_{t}$ and $\eta_{t}$ are not separately identified so the scale ratio $c_{\eta}$ is also not identified. Similarly, the bound for the asymptotic distribution of a standardized likelihood ratio test statistics due to Hansen (1992) which is applicable in such cases may result in under-rejection of the null or a subsequent power loss as noticed by Hansen himself. In addition, the test statistics is computationally very intense especially for this study, so I refrain from using it. Therefore, the inferences reported are based on the critical values obtained from $\chi_{1}^{2}$ and $\chi_{2}^{2}$ distributions.

Based on the LR test statistics for S\&P CNX 500 index, the null hypothesis of no persistence in mean returns $\left(\phi=c_{\eta}=0\right)$ is rejected at 10 percent level of significance using critical values from $\chi_{1}^{2}$ distribution. However, the null can not be rejected using critical values from $\chi_{2}^{2}$ distribution at $10 \%$ level of significance. For KSE 100 stock price index, the null is rejected at $10 \%$ level of significance using critical values from $\chi_{2}^{2}$ or even $\chi_{1}^{2}$ distribution. Therefore, after accounting for normality and volatility persistence there exist statistically significant persistent signals in both the markets. 


\subsubsection{Additional Tests on Normality and Volatility Persistence}

The tests for non-normality and volatility persistence are repeated considering model 4 as an alternative model. In this case model 5 is null model for non-normality and model 6 for homoskedasticity. The intuition behind these additional tests is to find the impact of excluding predictable component (from state space model) on the inferences from our model.

LR test statistics for normality and volatility persistence are reported in last two rows of column 5 in Tables 1 and 2 respectively for S\&P CNX 500 index and KSE 100 index. Based on these results we failed to reject hypotheses of normality and no volatility persistence for S\&P CNX 500 index. However, we reject both normality and no volatility persistence component in KSE 100 index. Figures 5 and 6 plot scales from model 4 for S\&P CNX 500, and KSE 100 index respectively which show the evidence of highly non-constant scales in these markets, however, scales for KSE 100 index shows spikes in different time periods exhibiting a tendency towards stock market crashes.

\subsubsection{Test for Leverage Effect}

Absence of leverage effect imply that negative shock do not necessarily lead to negative increase in future volatility than positive shocks of the same magnitude. This hypothesis can be tested setting $\gamma=0$, with $\gamma>0$ as alternate hypothesis that the leverage effect exists. The results (not reported for brevity) strongly reject the null hypothesis in favor of leverage effects both for S\&P CNX 500 and KSE 100 index.

\subsection{Discussions on Results}

The study results on hypothesis tests reveal that monthly KSE100 index excess returns from March 1991 through February 2004 do posses significant non-normality that is predictable even after accounting for conditional heteroskedasticity. Similarly, volatility persistence is also statistically significant. Leverage effects in volatility is insignificant, however, there is an evidence of statistically significant predictability at $10 \%$ level using critical values from $\chi_{2}^{2}$ as well as $\chi_{1}^{2}$ distribution. Statistically significant evidence of volatility 14 persistence exists in S\&P CNX 500 index but there is no evidence of non-normality in this market. The state space models do not show statistically significant persistent signal in return series after taking into account volatility persistence at $10 \%$ level of significance using critical values $\chi_{2}^{2}$ from distribution, but we are not able to reject the null of no persistent signal in returns using critical values from $\chi_{1}^{2}$ distribution for this market at $5 \%$ level of significance.

As shown in Figure 6 KSE 100 index show highly non-constant scales and when compared to S\&P CNX 500 index (Figure 5), the Figure shows random spikes in the years 1992, 1998, and 2000-2001. The plausible cause of these spikes are the external events during these years e.g. Gulf War, Asian Financial Crises, and crises after 
September 11, 2001 respectively that sensitized stock market agents that caused in instability in the stock prices and hence the market. Policymakers might be interested to address underlying policy issues enhance investor's confidence that would strengthen the stock markets in the country and help stabilize the economy.

\section{CONCLUSION}

In this study non-Gaussian state space or unobserved component models are employed to find possible predictability in two South Asian stock markets (S\&P CNX 500 and KSE 100). The state space models fully account for non-normality and volatility persistence that might be present in return series. S\&P CNX 500 index demonstrate estimated value of characteristic exponent $\alpha$ which is close to normal behavior, however, the excess return encompass ample evidence of stock return volatility characterized by GARCH-like behavior. KSE 100 excess stock returns demonstrate significant leptokurtosis. The estimated value of characteristic exponent is well away from the value pertaining to normal behavior in this market, and excess stock returns exhibit ample persistence in stock return volatility that can be characterized by a GARCH-like process. There is insignificant leverage effect in the stock return volatility in both the markets (S\&P CNX 500, and KSE 100) indicating that the negative shocks do not necessarily lead to greater increases in future volatility than the positive shocks of the equal magnitude. Unlike S\&P CNX 500, KSE 100 index exhibits scale spike that shows a tendency towards stock market crashes. Policymakers might be interested to address underlying policy issues that might help improving the major stock market of the country.

The study results on predictability of monthly stock returns are statistically significant in KSE100 index but such results are less significant for S\&P CNX 500 index. The efficiently estimated excess returns for S\&P CNX 500 are $0.01 \%$ per month $(0.12 \%$ per annum), and $0.015 \%$ per month $(0.18 \%$ per annum) for KSE 100 stock price index.

\section{Appendix A: Sorenson-Alspach Filtering Equations}

Let $\mathrm{y}_{\mathrm{t}}, \mathrm{t}=1, \ldots, \mathrm{T}$, be an observed time series and $\mathrm{x}_{\mathrm{t}}$ an unobserved state variable, stochastically determining $\mathrm{y}_{\mathrm{t}}$. Denote $\mathrm{Y}_{\mathrm{t}}=\left\{\mathrm{y}_{1}, \ldots, \mathrm{y}_{\mathrm{t}}\right\}$ The recursive formulae for obtaining one-step ahead prediction and filtering densities, due to Sorenson and Alspach (1971), are as follows:

$$
\begin{aligned}
& \mathrm{p}\left(\mathrm{x}_{\mathrm{t}} \mid \mathrm{Y}_{\mathrm{t}-1}\right)=\int_{-\infty}^{\infty} \mathrm{p}\left(\mathrm{x}_{\mathrm{t}} \mid \mathrm{x}_{\mathrm{t}-1}\right) \mathrm{p}\left(\mathrm{x}_{\mathrm{t}-1} \mid \mathrm{Y}_{\mathrm{t}-1}\right) \mathrm{d} \mathrm{x}_{\mathrm{t}-1} \\
& \mathrm{p}\left(\mathrm{x}_{\mathrm{t}} \mid \mathrm{Y}_{\mathrm{t}}\right)=\mathrm{p}\left(\mathrm{y}_{\mathrm{t}} \mid \mathrm{x}_{\mathrm{t}}\right) \mathrm{p}\left(\mathrm{x}_{\mathrm{t}} \mid \mathrm{Y}_{\mathrm{t}-1}\right) / \mathrm{p}\left(\mathrm{y}_{\mathrm{t}} \mid \mathrm{Y}_{\mathrm{t}-1}\right) \\
& \mathrm{p}\left(\mathrm{y}_{\mathrm{t}} \mid \mathrm{Y}_{\mathrm{t}-1}\right)=\int_{-\infty}^{\infty} \mathrm{p}\left(\mathrm{y}_{\mathrm{t}} \mid \mathrm{x}_{\mathrm{t}}\right) \mathrm{p}\left(\mathrm{x}_{\mathrm{t}} \mid \mathrm{Y}_{\mathrm{t}-1}\right) \mathrm{d} \mathrm{x}_{\mathrm{t}} .
\end{aligned}
$$


Finally, the log-likelihood function is given by:

$$
\log \mathrm{p}\left(\mathrm{y}_{1}, \ldots, \mathrm{y}_{\mathrm{T}}\right)=\sum_{\mathrm{t}=1}^{\mathrm{T}} \log \mathrm{p}\left(\mathrm{y}_{\mathrm{t}} \mid \mathrm{Y}_{\mathrm{t}-1}\right) \text {. }
$$

\section{REFERENCES}

Andrews, D.W.K., 2001. "Testing when a parameter is on the boundary of the maintained hypothesis”, Econometrica, Vol. 69, No. 3, 683-734.

Akgiray, V. and G. Booth, 1988. "The stable law model of stock returns", J. Business Econ. Statistics, 6, 51-7.

Barberis, N., 2000. "Investing for the long run when returns are predictable", Journal of Finance 54, 225-264.

Bidarkota, P.V. and J.H. McCulloch, 2004. "Testing for persistence in stock returns with GARCH-stable shocks", Quantitative Finance, Vol. 4, No. 3, 256- 265.

Bidarkota, P.V. and J.H. McCulloch, 1998. "Optimal univariate inflation forecasting with symmetric stable shocks”, Journal of Applied Econometrics, Vol. 13, No. 6, 659-670.

Buckle, D. J. 1995. "Beyesian inferences for stable distribution", Journal of American Statistical Association, 90, 605-13.

Cecchetti, S.G., P-s. Lam, and N.C. Mark, 1990. "Mean reversion in equilibrium asset prices", American Economic Review, Vol. 80, No. 3, 398- 418.

Cochran. S.J. and R.H. Defina, 1995. "Duration dependence in the US stock market cycle: a parametric approach", Applied Financial Economics, 5, 309-18.

Conrad, J. and G. Kaul, 1988. “Time-variation in expected returns”, Journal of Business, Vol. 61, No. 4, 409-425.

Crato, N., 1999. "Some International evidence regarding the stochastic memory of stock returns", Applied Financial Economics, 4, 33-9.

Danielsson, J., 1994. "Stochastic volatility in asset prices estimation with simulated maximum likelihood", J Econometrics, 64, 315-400.

De Vries, C.G., 1991. "On the relation between GARCH and stable process”, Journal of Econometrics.

Diebold, F.X. and J.A. Lopez, 1995. "Modeling volatility dynamics Macroeconomics: Developments", Tensions and Projects Ed K Hoover (Boston, MA: Kulwer-Academics) pp. 427072. 
Durbin, J. and S.J. Koopman, 2000. "Time series analysis of non-Gaussian observations based on state space models from both classical and Bayesian perspectives", Journal of The Royal Statistical Society, Series B, 62, Part 1, 3-56.

Engle, R.F. and T. Bollerslev, 1986. "Modeling the persistence of conditional variances", Econometric Reviews 5, 1-50.

Fama, E.F., 1991. "Efficient capital markets: II”, The Journal of Finance Vol. XLVI, No. 5, 1575-617.

French, K.R., G.W. Schwert and R.F. Stambaugh, 1987. "Expected stock returns and volatility", Journal of Financial Economics 19, 3-29.

Goose, D. and K.F. Kroner, 1995. "The relationship between GARCH and symmetric stable processes, finding the source of tails in financial data", J Empirical Finance, 2, 225-51.

Hamilton, J.D. and R. Susmel, 1994. "Autoregressive conditional heteroskedasticity and changes in regime”, Journal of Econometrics 64, 307-33.

Hansen, B.E., 1992. "The likelihood ratio test under nonstandard conditions: testing the Markov switching model of GNP", Journal of Applied Econometrics, Vol. 7 (supplement), S61-S82.

Harvey, A.C., 1989. "Forecasting, structural time series models and the Kalman filter", Cambridge University Press.

Jensen, D.W., and C.G. de V ries, 1991. "On the frequency of large stock returns: putting booms and busts into perspective", Review of Economics and Statistics, 73, 18-24.

Liu, S.M. and B.W. Brorsen, 1995. "Maximum likelihood estimation of a GARCHstable model", Journal of Applied Econometrics, Vol. 10, 273-85.

Lo, A., 1991. "Long-term memory in stock market prices", Econometrica, 59, 1279313.

Mandelbrot, B., 1963. "The variation of certain speculative prices”, Journal of Business 36, 394-419.

Lumsdainee, R., 1996. "Consistency and asymptotic normality of the quasi-maximum likelihood estimator in IGARCH $(1,1)$ ”, Econometrica, 64, 575-96.

Mandelbrot, B., 1963. "The variation of certain speculative prices", Journal of Business, 36, 394-419.

McCulloch, J.H., 1997. "Measuring tail thickness in order to estimate the stable index $\alpha$ : A critique", Journal of Business and Economic Statistics, Vol. 15, No. 1, 74-81. 
Ibid, 1996a. "Financial applications of stable distributions", in: G.S. Maddala and C.R. Rao (eds.), Handbook of Statistics, Vol. 14 (Elsevier, Amsterdam), 393-425.

Ibid, 1996b. "Numerical approximation of the symmetric stable distribution and density", in R. Adler, R. Feldman, and M.S. Taqqu (eds.), A Practical Guide to Heavy Tails: Statistical Techniques for Analyzing Heavy Tailed Distributions, Boston: Birkhauser.

Mantegna, R.N., and H.E. Stanley, 1995. "Scaling behavior in the dynamics of an economic index", Nature, 376, 46-9.

Nelson, D.B., 1991. "Conditional heteroskedasticity in asset returns: A new approach", Econometrica, Vol. 59, No. 2, 347-70.

Oh, C.S., 1994. "Estimation of time-varying term premia of U.S. Treasury securities: using a STARCH model with stable distributions", Unpublished Ph.D. dissertation, The Ohio State University.

Pagan, A.R., and G.W. Schwert, 1990. "Alternative models for conditional stock volatility”, Journal of Econometrics, 45, 267-90.

Sorenson, H.W., and D.L. Alspach, 1971. "Recursive Bayesian estimation using Gaussian sums", Automatica, 7, 465-79.

Summers, L.H., 1986. "Does the stock market rationally reflect fundamental values?" Journal of Finance, 41, 591-601.

Watson, M., 1986. "Univariate detrending methods with stochastic trends", Journal of Monetary Economics, 18, 49-75.

$\mathrm{Xu}, \mathrm{Y} ., 2004$. "Small levels of predictability and large economic gains", Journal of Empirical Finance, 11, 247-275.

Zolotarev, V.M., 1986. “One Dimensional Stable Laws”, (Providence RI: American Mathematical Society) (English Translation). 


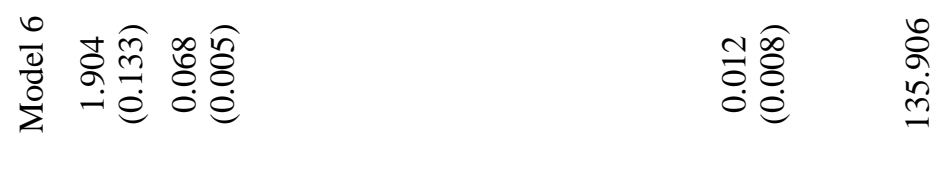

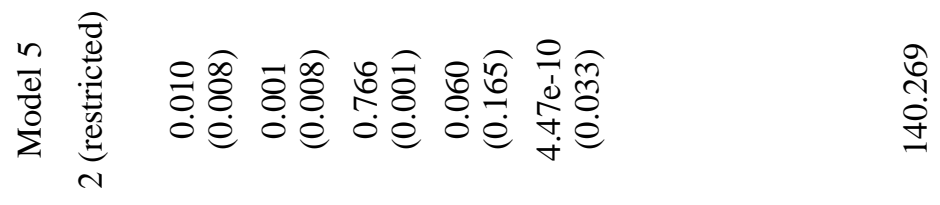

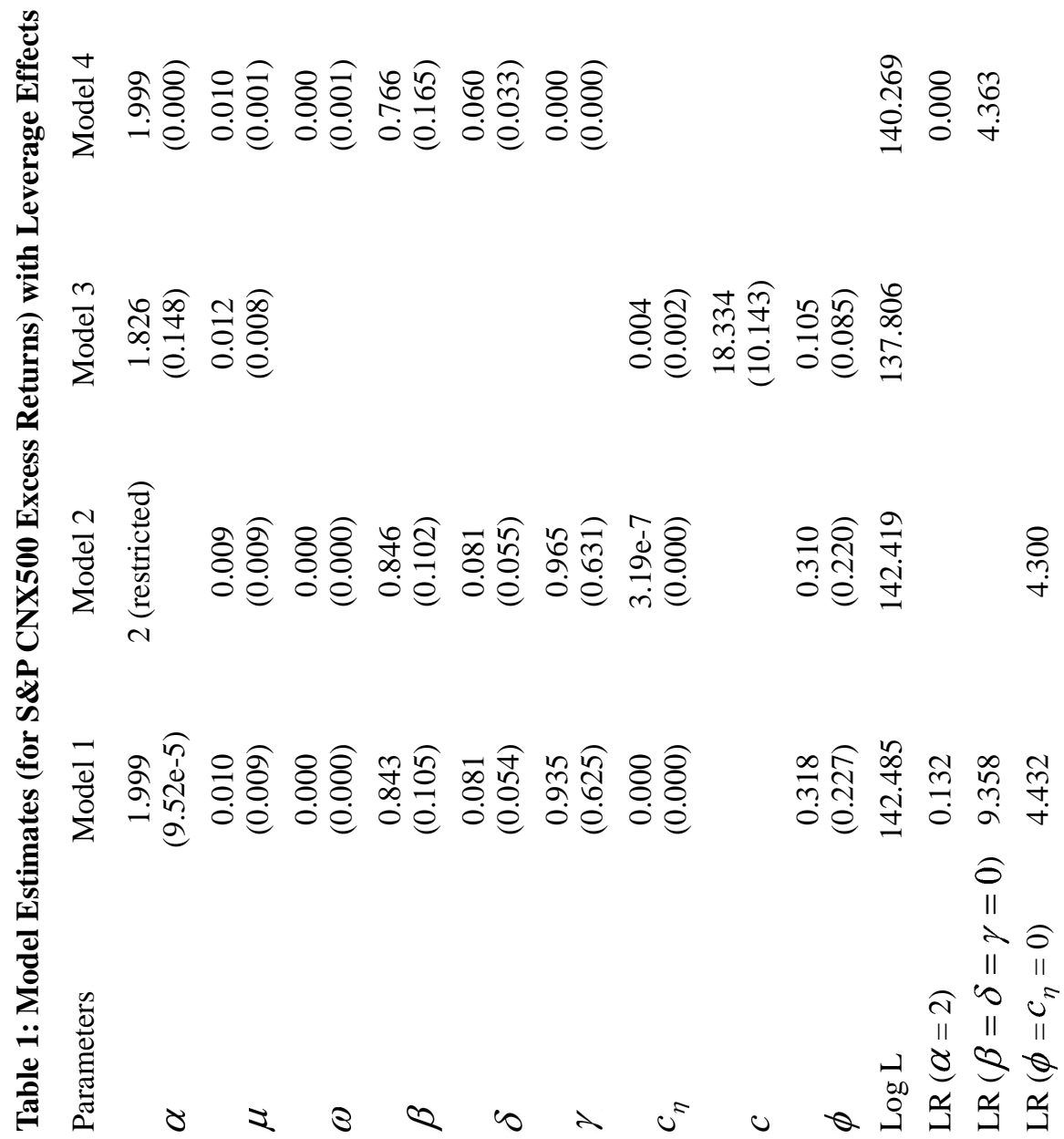


Notes on Table 1

1. The following unobserved component or state space model with non-normality (stable model) is employed to estimate the results shown in the table.

$$
\begin{gathered}
\mathrm{r}_{\mathrm{t}}=\mathrm{x}_{\mathrm{t}}+\varepsilon_{\mathrm{t}}, \quad \varepsilon_{\mathrm{t}} \sim \mathrm{cz}_{1 \mathrm{t}}, \quad \mathrm{z}_{1 \mathrm{t}} \sim \text { iid } \mathrm{S}_{\alpha}(0,1) \\
\left(\mathrm{x}_{\mathrm{t}}-\mu\right)=\phi\left(\mathrm{x}_{\mathrm{t}-1}-\mu\right)+\eta_{\mathrm{t}}, \quad \eta_{\mathrm{t}} \sim \mathrm{c}_{\eta} \mathrm{cz}_{2 \mathrm{t}}, \quad \mathrm{z}_{2 \mathrm{t}} \sim \text { iid } \mathrm{S}_{\alpha}(0,1)
\end{gathered}
$$

2. All estimates are rounded of $\mathrm{f}$ to the third decimal place.

3. Hessian-based standard errors for the parameter estimates are reported in parentheses. LR $\left(\phi=c_{\eta}=0\right)$ gives the value of the likelihood ratio test statistic. It is a test for no preaictabie components in excess returns. Under this null, the distribution of the LR test statistic is non-standard (see section 3.2 in the text for an elaboration).

4. P-values generated by estimating Gaussian versions of Models 1 and 2 with data simulated from the estimated Gaussian Model 2 are reported in parentheses.

5. LR ( $\alpha=2)$ gives the value of the likelihood ratio test statistic for the null hypothesis of normality.

6. The small-sample critical value at the 0.01 significance level for a sample size of 300 is reported to be 4.764 from simulations in McCulloch (1997).

7. $\operatorname{LR}(\beta=\delta=\gamma=0)$ is the test for no volatility persistence. This test is evaluated at $\chi_{3}^{2} \mathrm{p}$-values. 


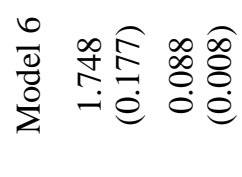

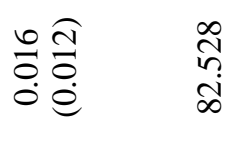

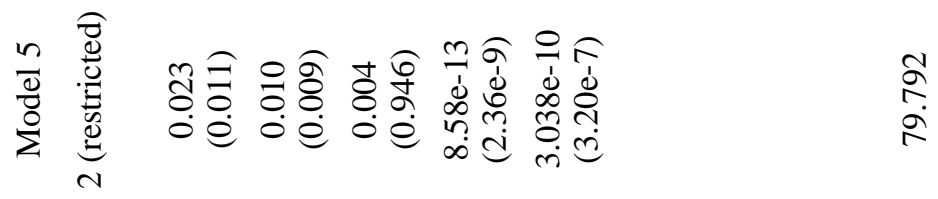

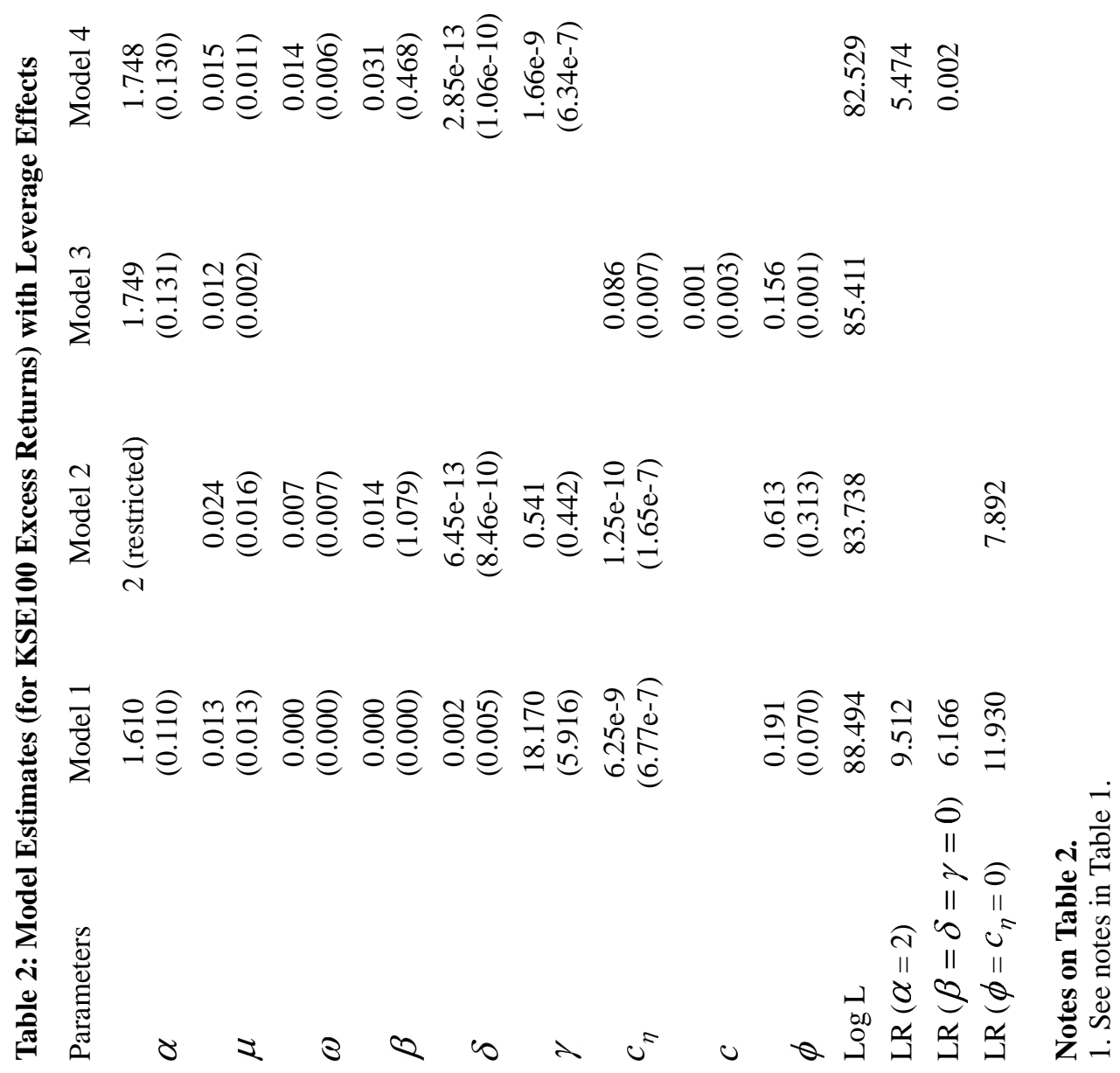



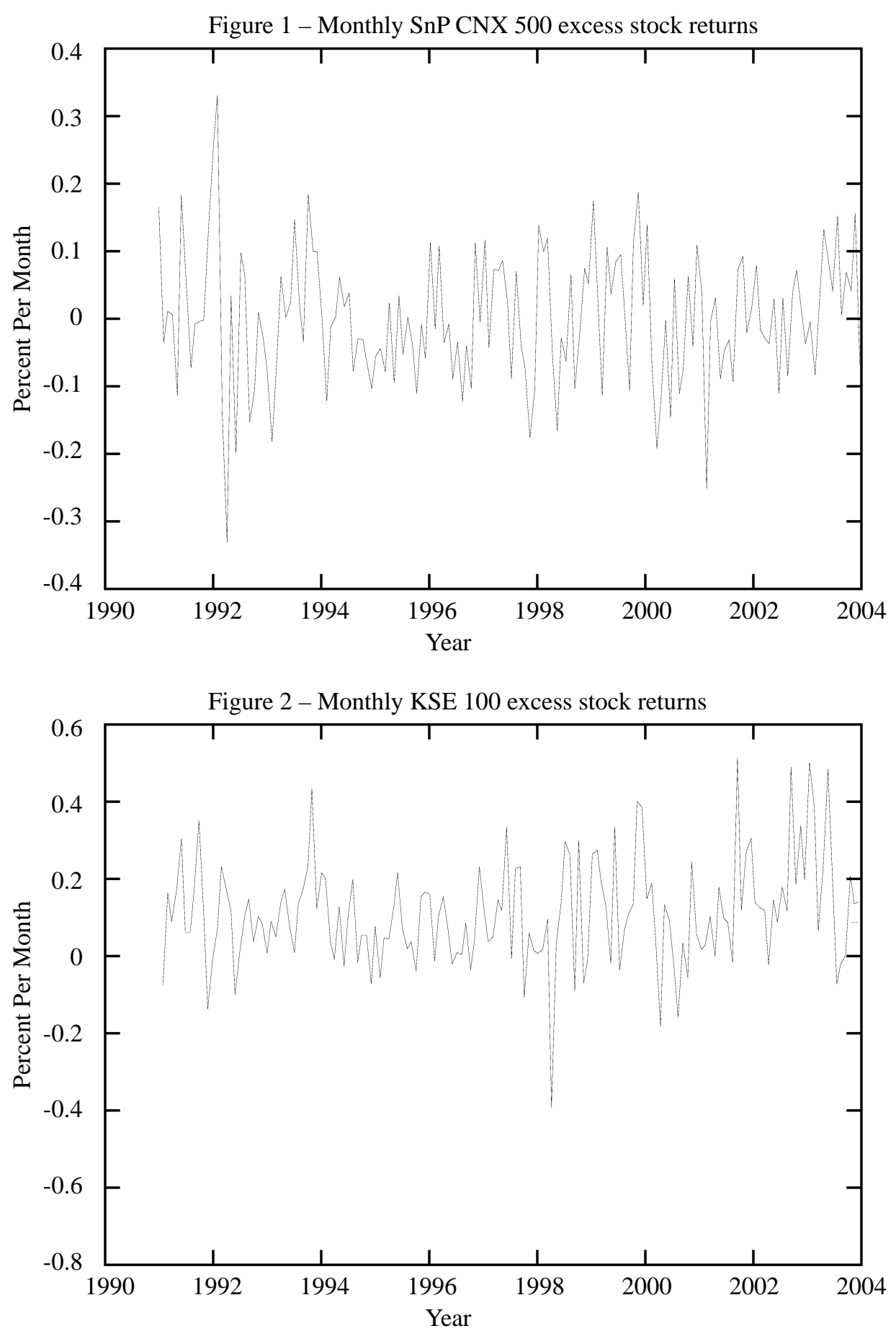
Figure 3 - SnP CNX 500 excess returns and filter estimates

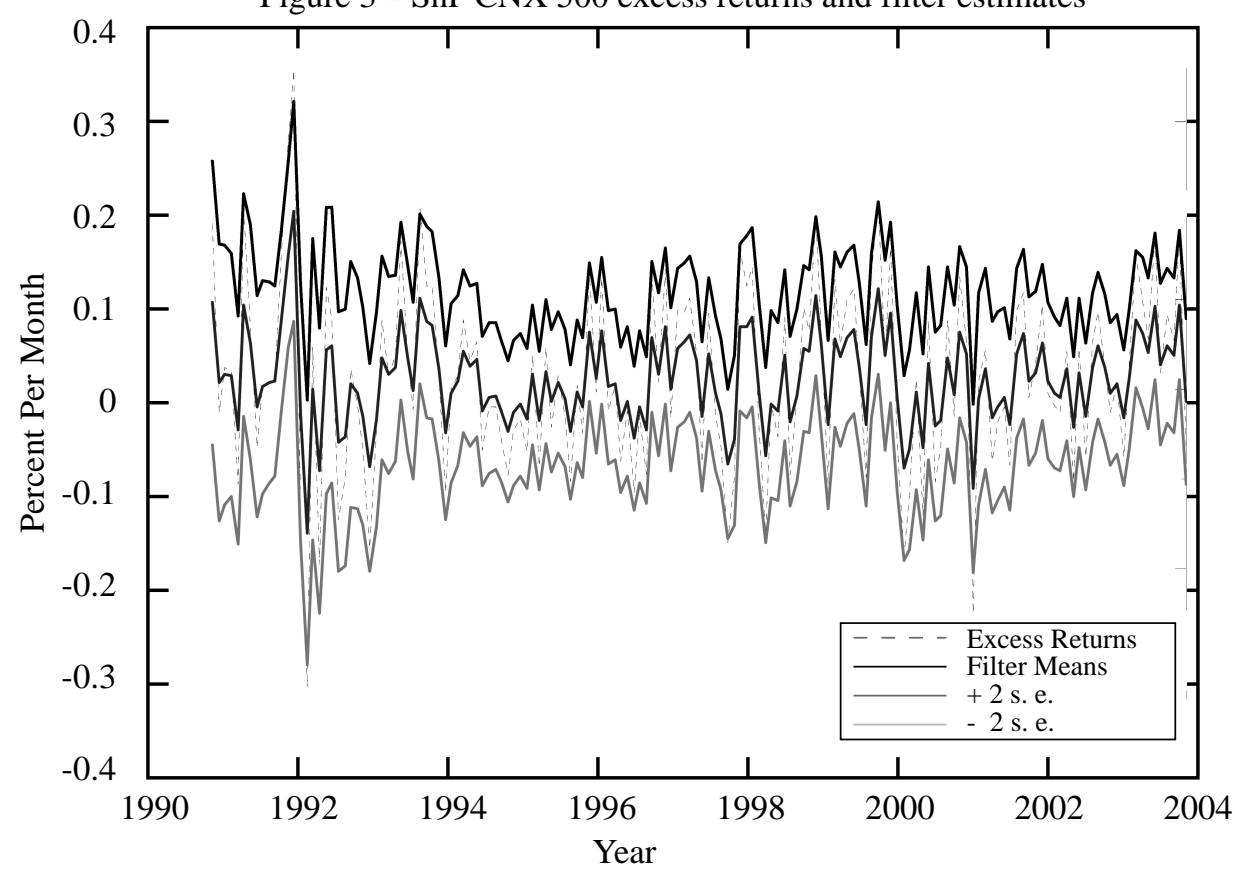

Figure 4 - KSE100 excess returns and filter estimates

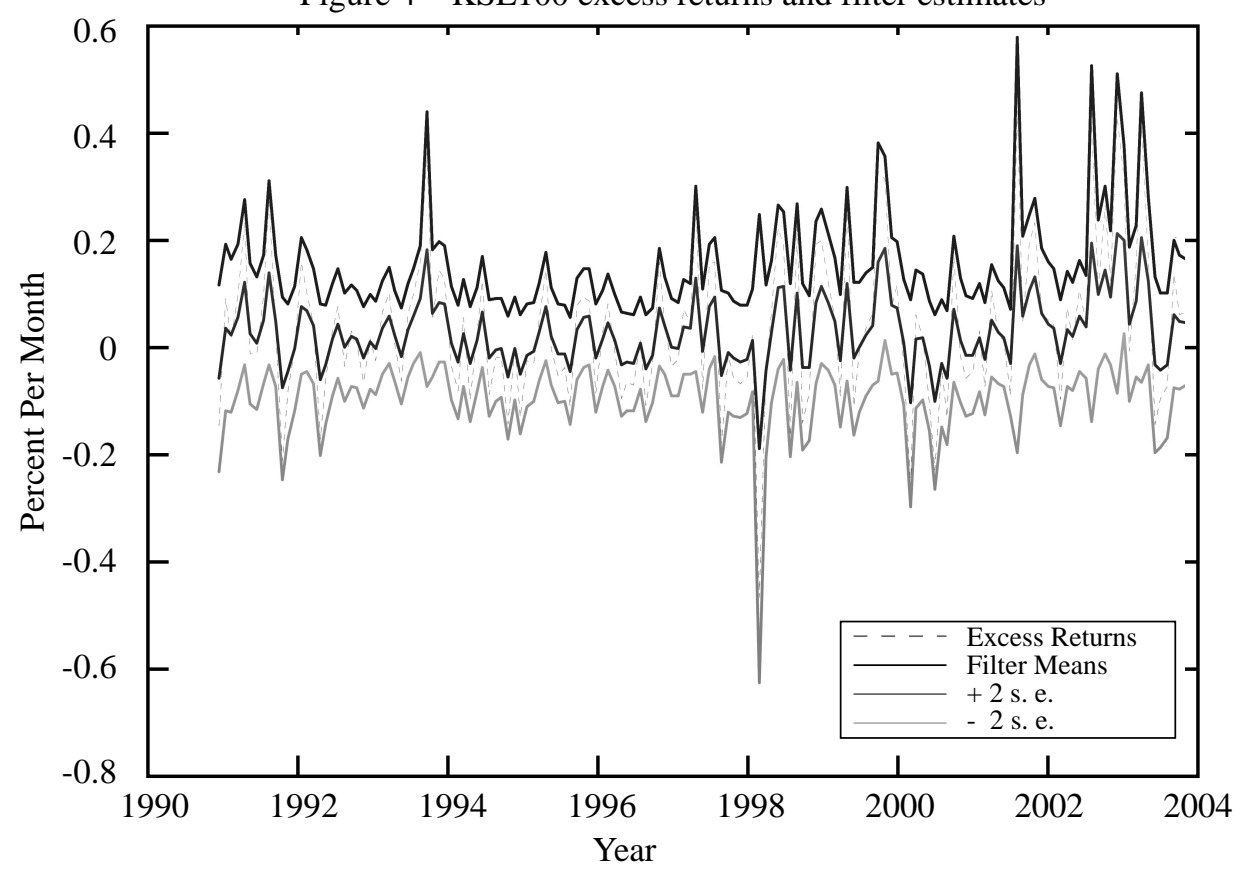


Figure 5 - Stock returns volatility-stable GARCH $(1,1)$ Model 4

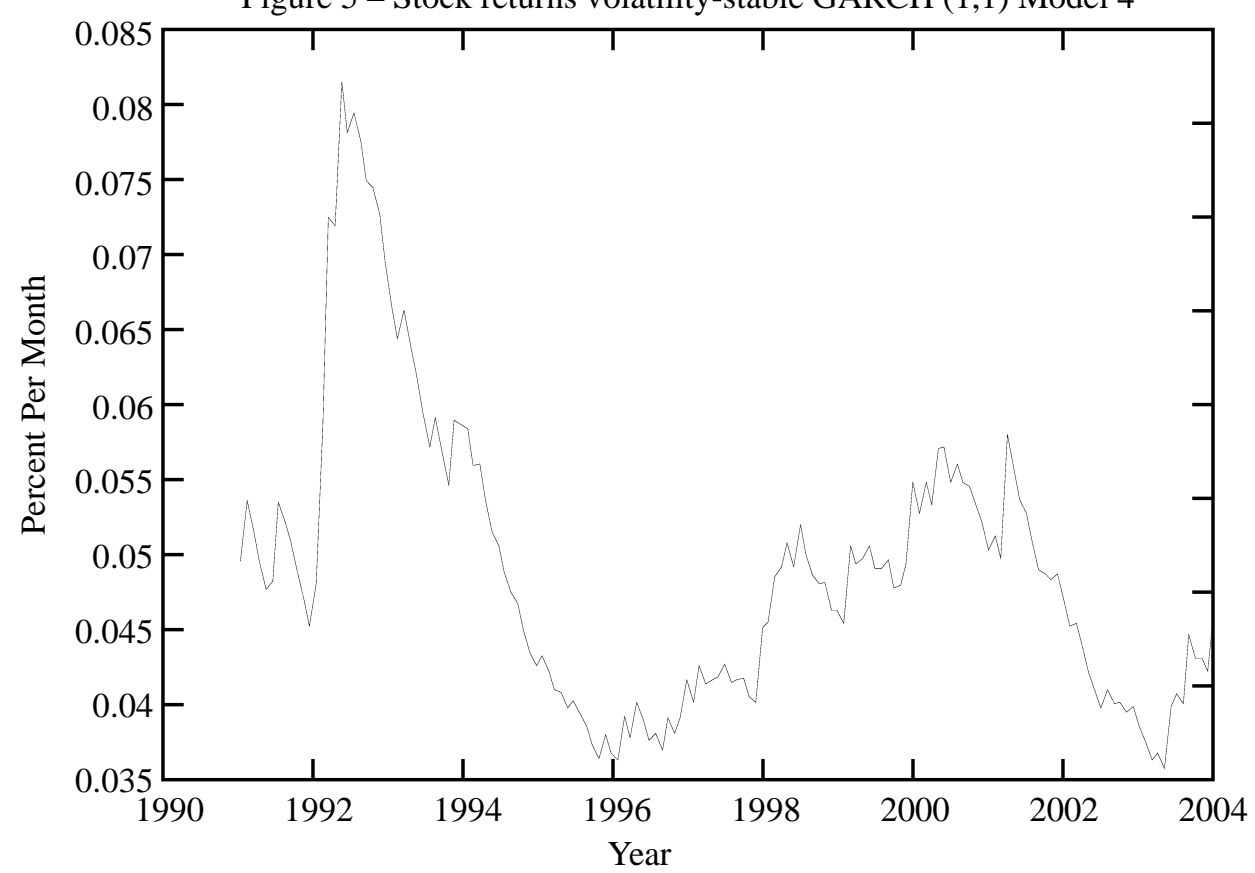

Figure 6 - Stock returns volatility-stable GARCH (1,1) Model 4

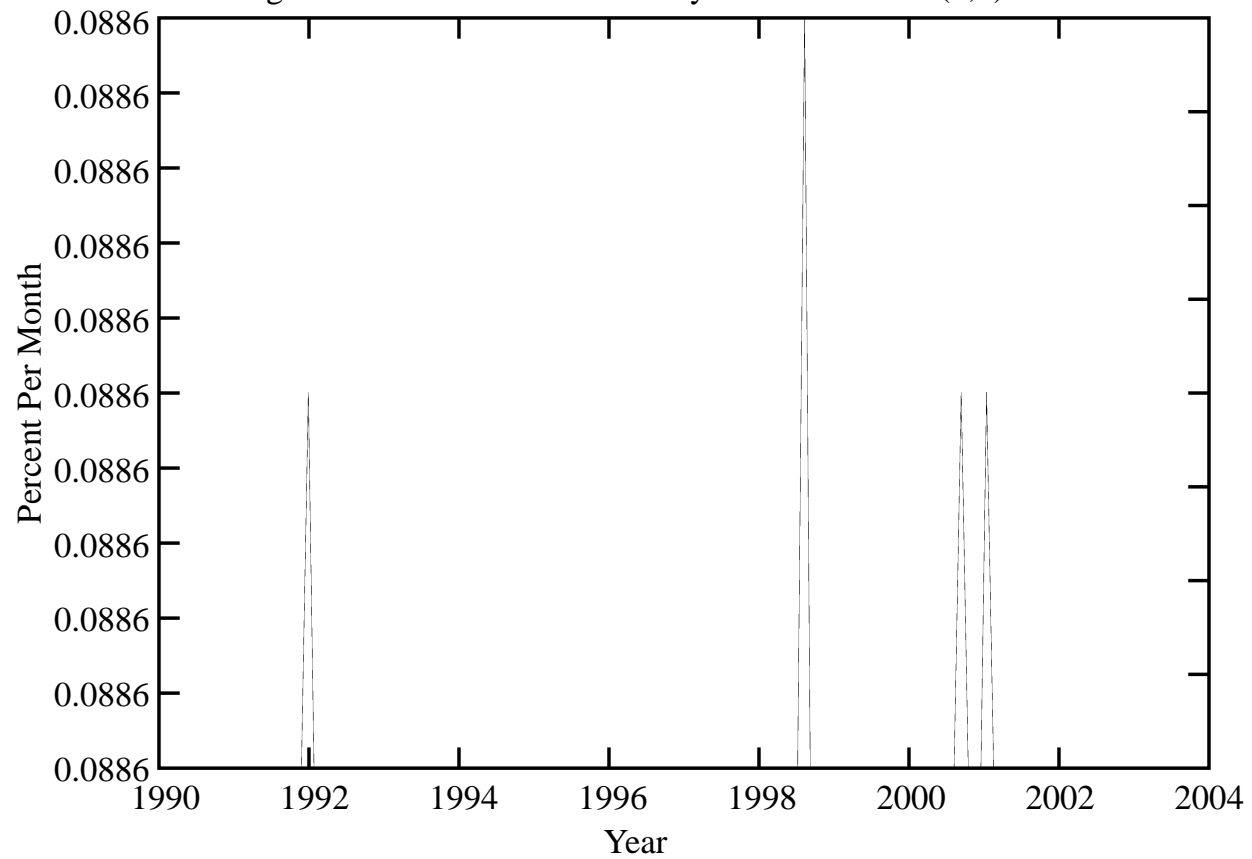

